\title{
HOW CAN IMMUNOLOGY CONTRIBUTE TO THE CONTROL OF TUBERCULOSIS?
}

\author{
Stefan H.E. Kaufmann \\ Tuberculosis poses a significant threat to mankind. Multidrug-resistant strains are on the rise, \\ and Mycobacterium tuberculosis infection is often associated with human immunodeficiency \\ virus infection. Satisfactory control of tuberculosis can only be achieved using a highly \\ efficacious vaccine. Tuberculosis is particularly challenging for the immune system. The \\ intracellular location of the pathogen shields it from antibodies, and a variety of T-cell \\ subpopulations must be activated to challenge the bacterium's resistance to antibacterial \\ defence mechanisms. A clear understanding of the immune responses that control the \\ pathogen will be important for achieving optimal immunity, and information provided by \\ functional genome analysis of $M$. tuberculosis will be vital in the design of a future vaccine.
}

\section{PERSISTENCE}

Microbes which resist the activated immune response can persist in the host. They are either controlled below the threshold that results in disease or exceed the threshold and produce disease. Disease outbreak can be due to slow progression of the microbe, weakening of the immune response, or both.
Max-Planck-Institute for Infection Biology, Department of Immunology, Schumannstrasse 21-22, D-10117 Berlin, Germany. e-mail:

kaufmann@mpiib-

berlin.mpg.de
Tuberculosis remains one of the main threats to mankind, and cannot be conquered without an efficacious vaccination strategy, which remains unavailable to date ${ }^{1,2}$. Of all bacteria, Mycobacterium tuberculosis is one of the most effective human pathogens, with one-third of the world's population (about 2 billion people) being infected. Most of the infected population neither develops disease nor becomes infectious, despite PERSISTENCE of the pathogen. It seems that the low ratio of diseased versus infected individuals is important for the successful survival of the microbe. M. tuberculosis targets MACROPHAGES, important effector cells in the immune system, as its preferred habitat. Whereas resting macrophages fail to harm M. tuberculosis, activated macrophages can control the growth of the microbe, although sterile eradication is seldom achieved. Several different T-cell populations are required for the successful control of the pathogen. This dynamic interplay underlying protection is the reason for the long-term persistence of M. tuberculosis. A better understanding of the interaction between the microbial invader and the host immune system will pave the way for the design of novel vaccines.

\section{Infection and disease}

Tuberculosis is caused by the acid-fast, rod-shaped bacillus $M$. tuberculosis. The microorganism is shielded by a unique wax-rich cell wall that is composed of longchain fatty acids, glycolipids and other components. Accordingly, approximately 250 genes within the $M$. tuberculosis genome are involved in fatty-acid metabolism. This robust shell contributes to the capacity of M. tuberculosis to survive in host phagocytes, and provides the source of glycolipid antigens for a specialized population of T cells. M. tuberculosis is a slowgrowing organism, with a replication time of approximately 20 hours. This slow growth forms the basis for the chronic nature of infection and disease, complicates microbiological diagnosis and necessitates long-term drug treatment.

Although scientific breakthroughs in the field have been rare, the recent release of the complete genome sequence of M. tuberculosis (BOX 1) has initiated a hunt for genes of interest for vaccine development, either as targets for gene knockout or as candidates for protective antigens ${ }^{3}$. Two clustered gene families that encode acidic, glycine-rich proteins make up $10 \%$ of the entire coding genome. They share a conserved amino-terminal 
MACROPHAGE

One of the main types of 'professional' phagocytes. Macrophages are long-lived and detrimental for many microbial pathogens. Intracellular bacteria including Mycobacterium tuberculosis, can survive within the macrophages, misusing them as their habitat.

VACCINE

A preparation that induces a specific for the particular antigen. Vaccines are usually targeted at infectious agents and composed of viable attenuated organisms, killed organisms or antigen (subunit or toxoid) preparations.

GRANULOMA

A chronic inflammatory tissue response at the site of implantation of certain foreign bodies, in particular at sites of long-term microbial persistence. Granulomas are typically well-organized structures composed of T cells and macrophages, some of which fuse to form giant cells.

CAESEOUS DETRITUS As a result of cellular disintegration and destruction, the central material of a granuloma becomes caeseous. In tuberculosis, this lipid-rich material provides a nutrientrich source for the pathogen. Further destruction might lead to liquefaction, thereby allowing microbial dissemination. protective immune response

sequence, that consists of a proline (Pro)-glutamic acid (Glu) or a Pro-Pro-Glu motif, but the carboxy-terminal segments show marked heterogeneity. The presumed functions of the two families are of potential interest for immunology $y^{4}$ first, they could cause antigenic variation in this rather invariant pathogen, and therefore facilitate evasion from the ongoing immune response; second, they could impair antigen processing. A large subgroup of the Pro-Glu family shares similarities with the Epstein-Barr virus nuclear antigens that impair peptide generation by proteasomes for major histocompatibility complex (MHC) class I processing for T cells. In M. marinum, Pro-Glu cognates were found to be upregulated in the GRANULOMA, and their deletion impaired mycobacterial growth in granulomas and in macrophages ${ }^{5}$.

Although tuberculosis can manifest itself at any tissue site, the lung represents both the main port of entry and an important site of disease manifestation. Extrapulmonary tuberculosis develops in less than $10 \%$ of all cases. Droplets containing minute numbers of bacilli are expelled by individuals suffering from active pulmonary tuberculosis. Alveolar macrophages engulf these droplets, but do not kill the pathogen. Specific T cells are stimulated in the draining lymph nodes and induce bacterial containment in small granulomatous lesions of the lung, but fail to achieve complete microbial eradication (FIG. 1). So, a dynamic balance between bacterial persistence and host defence develops. This balance might be lifelong, so that the individual is infected but does not suffer from clinical disease. Less than $10 \%$ of infected individuals will develop clinical disease during their lifetimes, but once disease does develop and remains untreated, it is fatal in $50 \%$ of patients (approximately 2 million deaths annually) (BOX 2). Disease outbreak is delayed because the progress of infection is very slow. In the adult, tuberculosis occurs typically as a result of a reactivation of existing foci, rather than as a direct outcome of primary infection ${ }^{6}$ (FIG. 1). Only in immunologically incompetent individuals, such as newborns, the aged and human immunodeficiency virus (HIV)-infected patients, does primary infection

\section{Box 1 | The Mycobacterium tuberculosis genome}

\section{Genetic description ${ }^{3}$}

Genome size: 4,411,532 bp; protein-coding genes, 3,959 (90.8\%); pseudogenes, six (excluding insertion sequence elements).

Genes with attributed functions, 2,441; conserved hypotheticals, 912; unknown genes, 606; genes absent from M. bovis BCG, 129.

\section{Differences between M. tuberculosis and BCG}

Whole genome DNA microarray techniques have identified 129 M. tuberculosisspecific open reading frames (ORFs) that are absent in the genome of the BCG vaccine strains ${ }^{11}$. These ORFs are clustered in 16 regions of deletion (RDs). A total of 61 ORFs (clustered in nine RDs) are missing in all M. bovis strains, including BCG, and 29 ORFs are missing in some BCG strains only, arguing against a direct link with attenuation. There are $39 \mathrm{ORFs}$ (clustered in three RDs) that are missing in all BCG strains, indicating a more direct link with attenuation. Obviously, the M. tuberculosis ORFs that are absent in BCG represent candidates not only for virulence factors, but also for protective antigens. habitually transform into disease. In individuals in whom infection converts into disease, cavitary lesions develop and bacteria increase in number in the CAESEOUS DETRITUS. Once cavitation reaches the alveoli, the patient becomes infectious, and a person with active disease infects up to 15 people annually ${ }^{1}$. The vicious circle then continues.

\section{The intracellular lifestyle of $M$. tuberculosis}

M. tuberculosis uses macrophages as its preferred habitat, which has two important implications for its survival ${ }^{7}$. First, macrophages, as professional phagocytes, are endowed with several surface receptors that facilitate antigen uptake, thereby rendering specific host-invasion strategies dispensable ${ }^{8,9}$. Cholesterol has been shown to act as a docking site for the pathogen, promoting receptor-ligand interactions ${ }^{10}$. The initial interaction with surface receptors influences the subsequent fate of M. tuberculosis within the macrophage. Interactions with the constant regions of immunoglobulin receptors (FcRs) and Toll-like receptors stimulate host-defence mechanisms, whereas those with complement receptors promote mycobacterial survival ${ }^{11-14}$. The second consequence, which warrants more sophisticated coping mechanisms, is the survival of $M$. tuberculosis within the PHAGOSOME, as this constitutes a harsh environment that is detrimental to many microbes ${ }^{7}$. M. tuberculosis solves this obstacle by arresting the phagosome at an early stage of maturation, and by preventing fusion of the phagosome with lysosomes $^{11,15-17}$ (FIG. 2). Residing in the early recycling ENDOSOME, $M$. tuberculosis has ready access to iron, which is essential for intracellular survival ${ }^{7,18}$. Iron is also required in various host-defence mechanisms $\mathrm{s}^{7,19}$. To successfully compete for iron with its host, the pathogen possesses specialized iron-scavenging molecules $^{20}$. The arrest of phagosomal maturation is not an all-or-nothing event, and some mycobacterial phagosomes can proceed to develop to the more mature stages of the phagolysosome. Phagosomal maturation is promoted by activation with interferon- $\gamma($ IFN $-\gamma)$, which stimulates anti-mycobacterial mechanisms in macrophages, notably reactive oxygen intermediates $(\mathrm{ROI})$ and reactive nitrogen intermediates $(\mathrm{RNI})^{7,21}$ (FIG. 1). The role of RNI in the control of human tuberculosis remains controversial, despite a body of evidence from animal experiments that supports its role in the control of M. tuberculosis ${ }^{22-24}$. However, even IFN- $\gamma$-activated macrophages fail to fully eradicate their resident $M$. tuberculosis organisms $\mathrm{s}^{25}$. Persistent microbes might proceed to a stage of DORMANCY with a reduced metabolic activity that facilitates their survival under conditions of nutrient and oxygen deprivation. These bacteria can persist without producing disease and therefore create a state of LATENCY. Nevertheless, the risk of disease outbreak at a later time remains. In vitro experiments indicate that mycobacteria switch to lipid catabolism and nitrate respiration to ensure their survival $^{26,27}$. Lipids are abundant in the caeseous detritus of granulomas, providing a rich source of nutrients during persistence. 
ENDOSOME

Large molecules are engulfed by endocytosis. They are transported to an endosomal compartment that matures and fuses with lysosomes that contain degrading enzymes. Endosomal and phagosoma pathways are interconnected.

PHAGOSOME

Large particles, such as bacteria, are engulfed by phagocytosis and are transported to phagosomes. Phagosomal and endosomal pathways undergo interconnected maturation an merge prior to fusion with lysosomes. M. tuberculosis can modify this pathway and prevent phagosomal maturation.

\section{DORMANCY}

Dormant microorganisms persist in the host in a metabolically reduced state. They generally do not cause clinical disease and are largely ignored by the immune system.

LATENCY

Latent infection with a microbe does not cause clinical disease because the microbe usually persists in a dormant stage.

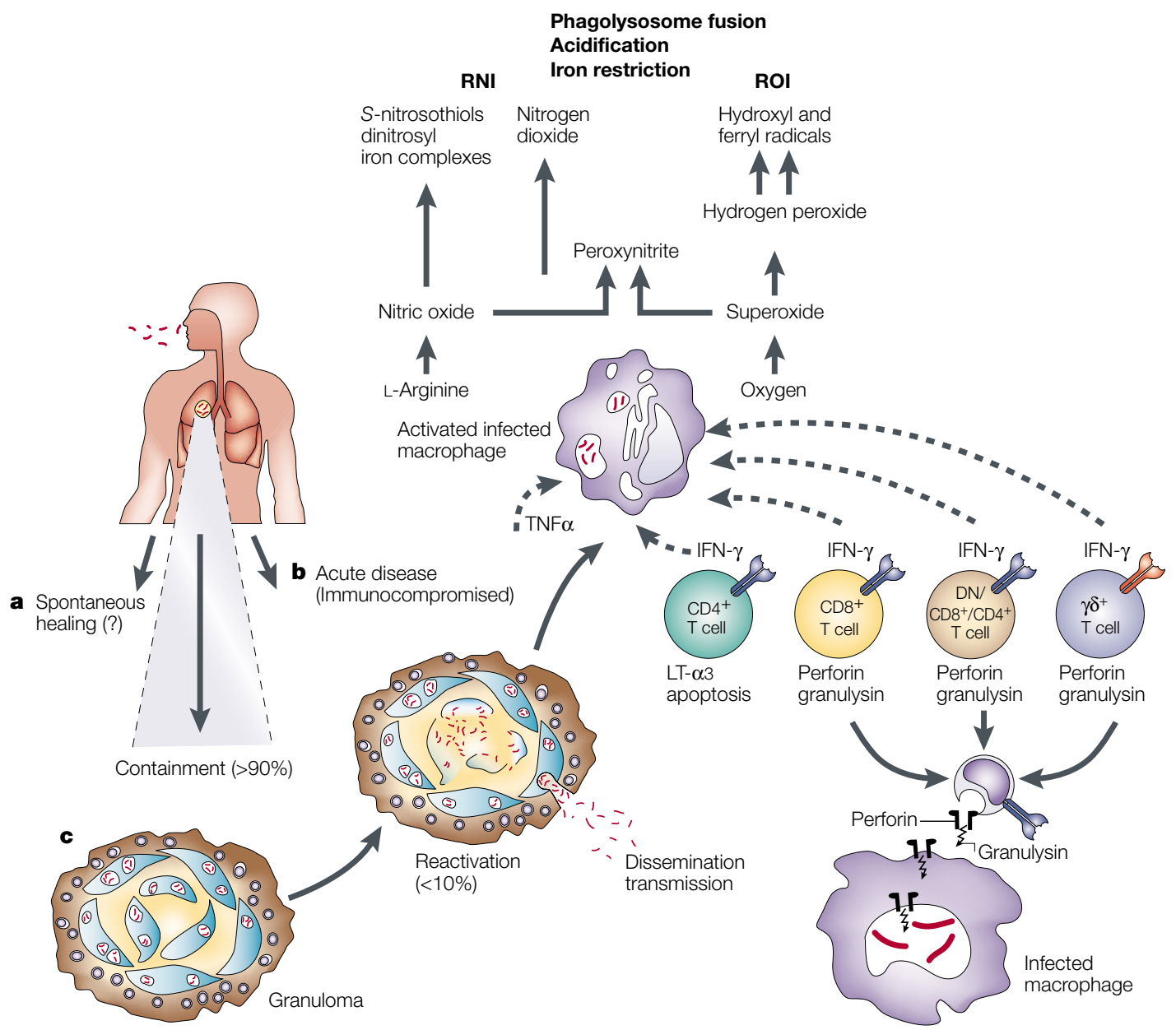

Figure 1 | Main features of tuberculosis: from infection to host defence. There are three potential outcomes of infection of the human host in Mycobacterium tuberculosis. a | The frequency of abortive infection resulting in spontaneous healing is unknown, but is assumed to be minute. $\mathbf{b}$ | In the immunocompromised host, disease can develop directly after infection. c | In most cases, mycobacteria are initially contained and disease develops later as a result of reactivation. The granuloma is the site of infection, persistence, pathology and protection. Effector T cells (including conventional CD4 ${ }^{+}$and $C D 8^{+} \mathrm{T}$ cells, and unconventional T cells, such as $\gamma \delta$ T cells, and double-negative or CD4/CD8 single-positive T cells that recognize antigen in the context of CD1) and macrophages participate in the control of tuberculosis. Interferon- $\gamma$ (IFN- $\gamma$ ) and tumour-necrosis factor- $\alpha$ (TNF- $\alpha$ ), produced by T cells, are important macrophage activators. Macrophage activation permits phagosomal maturation and the production of antimicrobial molecules such as reactive nitrogen intermediates (RNI) and reactive oxygen intermediates (ROI). LT- $\alpha 3$, lymphotoxin- $\alpha 3$

\section{The T-cell response to $M$. tuberculosis}

Few foreign agents induce such a broad immune response as $M$. tuberculosis. It seems that the strong selective pressure arising from mycobacterial-host interactions has resulted in a requirement for the participation of unconventional $\mathrm{T}$ cells as well as conventional T cells in defence $e^{1,7,28,29}$.

Conventional T cells. Both $\mathrm{CD} 4^{+}$and $\mathrm{CD} 8^{+} \mathrm{T}$ cells have a role in fighting $M$. tuberculosis infection. Residence of M. tuberculosis within the phagosome ensures that antigens have ready access to the MHC class II antigen-processing machinery ${ }^{25}$ (FIG. 3). Mycobacteria-specific CD4 ${ }^{+}$ $\mathrm{T}$ cells are typically of the helper $\mathrm{T}$ cell $\left(\mathrm{T}_{\mathrm{H}} 1\right)$ type, in that they are potent IFN- $\gamma$ producers (FIG. 1 ). IFN- $\gamma$ is a central factor in the activation of anti-mycobacterial activities of macrophages, and hence considered crucial for protection against tuberculosis. $\mathrm{T}_{\mathrm{H}} 2$ cytokines, such as interleukin (IL)-4 and IL-10 are scarce, though not fully absent ${ }^{30,31}$. The differentiation of $\mathrm{CD} 4^{+} \mathrm{T}$ cells into $\mathrm{T}_{\mathrm{H}} 1$ cells is promoted by the early cytokine milieu, which includes IL-12, IL-18 and co-stimulatory molecules $^{25,32}$. This milieu is partially induced through Tolllike receptors ${ }^{12,33,34}$. It seems that activation of $\mathrm{T}_{\mathrm{H}} 1$ cells following Bacille Calmette-Guérin (BCG) vaccination, or during $M$. tuberculosis infection, is suboptimal, and further experiments will be required to establish why this is so. Although the central role of IFN- $\gamma$ in the control of M. tuberculosis is beyond doubt ${ }^{25,35}$, other cytokines, in particular tumour-necrosis factor- $\alpha$ (TNF- $\alpha$ ) and lymphotoxin (LT)- $\alpha 3$, participate by regulating the formation and maintaining the structural integrity of granulomas ${ }^{36-39}$ (FIG. 1). The importance of TNF- $\alpha$ in containing M. tuberculosis in humans was 
DALY

(Disability-adjusted life years). A measure describing years of life lost by death, disease or disability. It provides the best measure of cost-effectiveness assessments of disease and of preventive and therapeutic regimes notably shown by the increased risk of reactivation of tuberculosis in rheumatoid arthritis patients who were undergoing anti-TNF- $\alpha$ therapy ${ }^{40,41}$.

Despite its residence within phagosomes, $M$. tuberculosis is capable of stimulating MHC-class-I-restricted $\mathrm{CD}^{+} \mathrm{T}$ cells, and compelling evidence shows that these T cells participate in protection ${ }^{1,25,32}$ (FIG. 3). On the basis of indirect evidence, it has been proposed that M. tuberculosis remains inside the phagosome and perforates the phagosomal membrane to gain access to cytosolic nutrients $^{42}$. This mechanism could also permit mycobacterial antigens to access the MHC class I pathway. Consistent with such a pathway, transfer of molecules from the cytoplasm into phagosomes which harbour BCG has been described ${ }^{43}$. By contrast, however, no evidence was found for leakage of fluorescent dyes out of the mycobacterial phagosome into the cytoplasm when they were co-loaded as reporter molecules with M. tuberculosis (Schaible et al., unpublished observations). This argues against direct passage of mycobacterial antigens through the phagosomal membrane into the cytosolic MHC class I pathway, and alternative pathways must be assumed. Lipoproteins and glycolipids are released from the mycobacteria and are incorporated into vesicles. These antigens are shuttled within the cell and also travel to bystander cells ${ }^{44-47}$. Engulfment of antigen-loaded vesicles by bystander antigen-presenting cells has been shown to induce MHC-class-I-restricted CD8 ${ }^{+} \mathrm{T}$-cell responses in other systems ${ }^{48}$. Vesicles are released, in particular, from apoptotic cells that are abundant in caeseous lesions of tuberculosis patients ${ }^{48,49}$. It is therefore tempting to speculate that at least certain mycobacterial antigens are transferred to dendritic cells (DCs), thereby promoting antigen presentation through MHC class I to $\mathrm{CD}^{+} \mathrm{T}$ cells (FIG. 3). Different pathways probably operate to ensure adequate MHC class I presentation of mycobacterial antigens. Antigen transfer is important for the priming of $\mathrm{CD}^{+} \mathrm{T}$-cell responses because it allows efficient stimulation by DCs, whereas direct MHC I

\section{Box 2 | Tuberculosis: the global figures}

The causes of death according to the World Health Report 2000 (REF. 2)

- Total cases of death: 56 million

- Total cases of death caused by infectious diseases: 17 million (30\%)

- Three main killers among infectious diseases: $\mathrm{HIV}^{\star}: 2.7$ million (4.8\%); Tuberculosis $^{\star}$ : 2.2 million (4.0\%); Malaria: 1.1 million (1.9\%).

Burden of diseases in DALY (disability-adjusted life years) ${ }^{2}$

- Total DALY: 1.4 billion

- Infectious diseases: 540 million (40\%); HIV ${ }^{\star} 89.8$ million (6.2\%);

Tuberculosis ${ }^{\star}: 45$ million $(3.1 \%)$.

Tuberculosis, in context ${ }^{1}$

- 2 billion individuals infected with $M$. tuberculosis (less than $10 \%$ risk of developing disease following infection and less than $5 \%$ risk of death after infection)

- 8 million new tuberculosis cases per year ( 1 new case every 4 seconds)

- 2.2 million $^{\star}$ deaths per year ( 1 death every 10 seconds)

-10-15 individuals infected annually by a single untreated patient

${ }^{\star}$ Includes the 500,000 people co-infected with M. tuberculosis and HIV. processing by infected macrophages predominates in the effector phase, therefore focusing $\mathrm{CD} 8^{+} \mathrm{T}$ cells on infected target cells.

$\mathrm{CD}^{+} \mathrm{T}$ cells, similar to $\mathrm{CD} 4^{+} \mathrm{T}$ cells, can produce IFN- $\gamma$, but their main function is target cell killing ${ }^{25,32}$. By lysing infected host cells, $\mathrm{CD} 8^{+} \mathrm{T}$ cells could facilitate the translocation of $M$. tuberculosis from incapacitated cells to more proficient effector cells ${ }^{25}$. More recently, human $\mathrm{CD}^{+} \mathrm{T}$ cells that express granulysin and perforin have been shown to kill M. tuberculosis directly ${ }^{50-52}$ (FIG. 1). Granulysin is responsible for bacterial killing and presumably gains access to $M$. tuberculosis that resides within macrophages through pores formed by perforin. Antigen-specific T cells achieve killing of infected macrophages mostly through apoptotic mechanisms, and experiments showed that apoptotic mechanisms can also induce growth inhibition of M. tuberculosis ${ }^{53}$. Finally, ATP released by T cells can induce killing of mycobacteria $^{54}$.

Knockout mice that are deficient in classical MHC class I, transporter of antigen processing (TAP) or CD8 $\alpha$, are less susceptible to $M$. tuberculosis infection than $\beta_{2}$-microglobulin $\left(\beta_{2} \mathrm{~m}\right)$ knockout mice ${ }^{5-58} \cdot \beta_{2} \mathrm{~m}$ stabilizes MHC class I surface expression, and therefore its deficiency results in the absence of mature $\mathrm{CD}^{+} \mathrm{T}$ cells. However, $\beta_{2} \mathrm{~m}$ also supports the surface expression of non-classical MHC class Ib and various MHC-class I-like molecules that control unconventional $\mathrm{T}$ cells ${ }^{25}$. $\beta_{2} \mathrm{~m}$ is also involved in iron metabolism, as it stabilizes surface expression of the product of the atypical human leukocyte antigen (HLA) class I hereditary haemochromatosis gene (HFE) that regulates iron uptake ${ }^{19}$. The increased susceptibility of $\beta_{2}$ m-deficient mice to tuberculosis is therefore caused by a number of factors, and is only partially attributable to a lack of $\mathrm{CD}^{+} \mathrm{T}$ cells.

Unconventional $T$ cells. In certain mouse strains (notably $\mathrm{C} 57 \mathrm{BL} / 6), \mathrm{CD}^{+} \mathrm{T}$ cells that recognize $\mathrm{N}$-formylated peptides presented by the non-classical MHC class I molecule H2-M3, have been found to dominate the primary immune response against Listeria monocytogenes $^{25}$. Formylation of proteins represents a characteristic feature of prokaryotic proteins, and aside from mitochondria that are of prokaryotic origin, the motif is lacking in mammalian antigens. Specificity for formylation therefore directs the immune response towards microbial invaders. Recent evidence indicates that such T cells also participate in mouse tuberculo$\operatorname{sis}^{59,60}$. Although direct homologues of H2-M3 have not been identified in humans, $\mathrm{CD}^{+} \mathrm{T}$ cells restricted by non-classical HLA molecules participate in the response against $M$. tuberculosis in humans ${ }^{61,62}$.

T cells with specificity for mycobacterial glycolipids presented by CD1 molecules seem to have a unique role in human tuberculosis ${ }^{29,63-65}$. Group 1 CD1 molecules, comprising CD1a, CD1b and CD1c, are found in primates and guinea-pigs, but not in mice ${ }^{63-65}$. Generally, CD1-glycolipid-specific T cells produce IFN- $\gamma$ and express cytolytic activity. Group 1 CD1 molecules typically present glycolipids that are abundant in the mycobacterial cell wall, such as phosphatidylinositol 


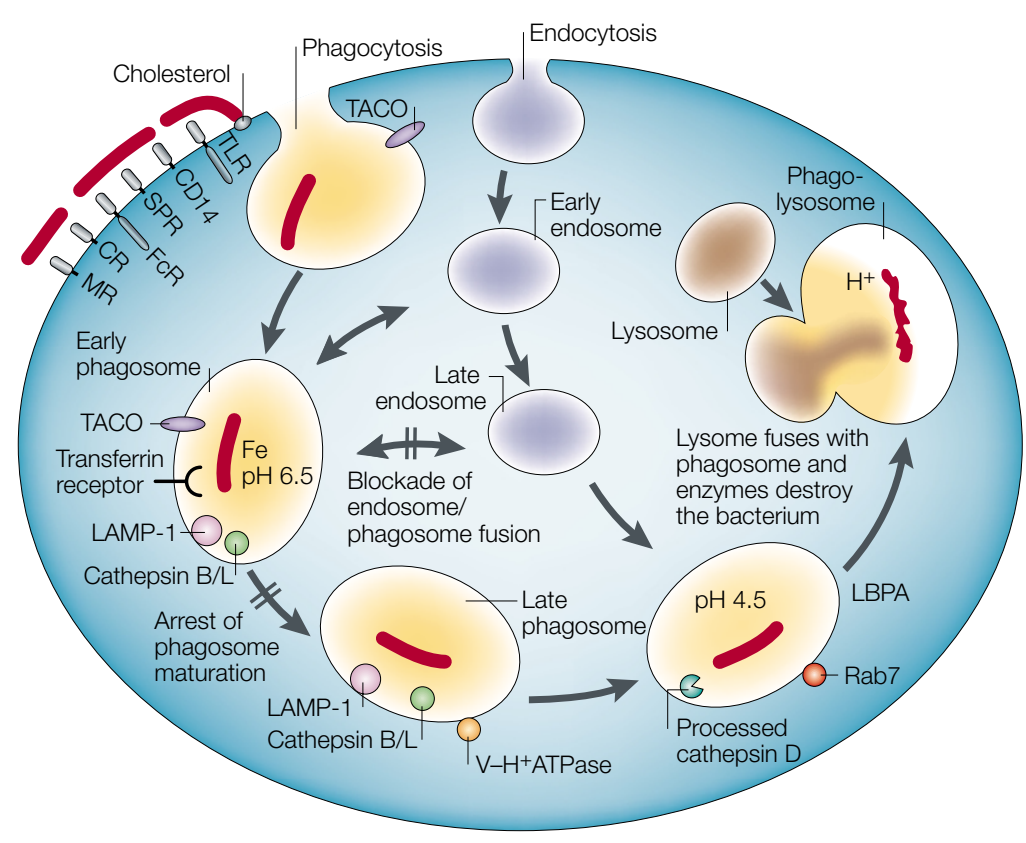

Figure 2 | The intracellular lifestyle of Mycobacterium tuberculosis. This figure illustrates phagosome and endosome maturation and the influence of $M$. tuberculosis on this process. Phagocytosis of larger particles is a unique property of specialized cell types - the 'professional' phagocytes - whereas virtually all eukaryotic cells are capable of engulfing small particles and fluids that end up in the endosomal pathway. Both the endosomal and phagosomal pathways undergo interconnected maturation processess that merge at a late stage, prior to fusion with lysosomes. Various surface receptors participate in the early encounter between $M$. tuberculosis and macrophages. Cholesterol serves as a docking site that facilitates interactions between mycobacteria and surface receptors ${ }^{10}$. Once engulfed, $M$. tuberculosis ends up in a phagosome, the maturation of which is arrested at an early stage. The early phagosome-harbouring mycobacteria characteristically retains TACO, which apparently prevents its further maturation ${ }^{17}$. M. tuberculosis inhibits phagosomal acidification ${ }^{15,21}$ (which occurs by means of a $\mathrm{V}-\mathrm{H}^{+}$ATPase) and prevents fusion with the endosomal pathway. The arrest of phagosomal maturation is, however, incomplete and some phagosomes mature to form phagolysosomes. Phagosome maturation is promoted in activated macrophages, particularly after IFN- $\gamma$ stimulation ${ }^{21}$. Although phagosome and endosome maturation form a continuum, distinct steps can be distinguished by means of different markers and tracers, some of which are shown. CR, complement receptor; FcR, receptor for the constant fragment of immunoglobulin; LAMP-1, lysosomal-associated membrane protein 1; LBPA,

lysobiphosphatic acid; MR, mannose receptor; Rab7, member of the small GTPase family; SPR, surfactant protein receptor; TACO, tryptophane, aspartate-containing coat protein; TLR, Toll-like receptor; $\mathrm{V}-\mathrm{H}^{+}$ATPase, vacuolar ATP-dependent proton pump.

mannosides, lipoarabinomanan, mycolic acids and hexosyl-1-phosphoisoprenoids ${ }^{64,65}$ (FIG. 3). The different CD1 molecules display distinct intracellular locations, with CD1a being almost exclusively expressed on the cell surface and in the early recycling endosome, CD1b residing primarily in late endosomes/lysosomes and $\mathrm{CD} 1 \mathrm{c}$ being localized on the cell surface and in endosomes at different stages of maturation ${ }^{46,66}$. CD1a and $\mathrm{CD} 1 \mathrm{c}$ have ready access to mycobacterial glycolipids as M. tuberculosis arrests phagosomal maturation at early stages. Mycobacteria shed glycolipids inside the phagosome, and these enter the late endosome/lysosome, where they can also interact with $\mathrm{CD}_{1} \mathrm{~b}^{46}$. Vesicles containing shed glycolipids can be released, and therefore deliver their antigenic cargo to bystander cells. Group 1 CD1 molecules are abundantly expressed on DCs, but are virtually absent on macrophages, and CD1b surface expression is downregulated in cells infected with
M. tuberculosis ${ }^{67}$. The transfer of glycolipids from infected macrophages to bystander DCs therefore constitutes an important mechanism for promoting CD1 presentation $^{46}$ (FIG. 3). Group 2 CD1 molecules (CD1d) seem to have a minor role in tuberculosis ${ }^{56}$.

$\mathrm{T}$ cells that express a $\gamma \delta \mathrm{TCR}$, also participate in the immune response against M. tuberculosis ${ }^{28}$ (FIG.3). In the mouse, these $\mathrm{T}$ cells partially protect against high, but not low, inocula of $M$. tuberculosis, and regulate granuloma formation ${ }^{68,69}$. Unlike mouse $\gamma \delta$ T cells, human $\gamma \delta$ T cells are stimulated by a unique group of non-proteinaceous antigens that contain phosphate, apparently independent of any restriction elements. These 'phospholigands' include different prenyl pyrophosphates and nucleotide conjugates, all of which are abundant in mycobacteria. The phospholigands stimulate $\gamma \delta \mathrm{T}$ cells that express the $\mathrm{V} \gamma 2 \delta 2$ chain combination independently of their fine antigen specificity. $\mathrm{V} \gamma 2 \delta 2 \mathrm{~T}$ cells comprise an important population of all $\gamma \delta \mathrm{T}$ cells, and constitute about $5 \%$ of all T cells in the peripheral blood in adults ${ }^{28}$. This large $\gamma \delta$ T-cell population readily produces IFN- $\gamma$ after stimulation with phospholigands and expresses granule-dependent mycobacteriocidal activity ${ }^{70}, \gamma \delta \mathrm{T}$ cells could, therefore, be responsible for mobilizing the first line of defence against tuberculosis. In this respect, $\gamma \delta \mathrm{T}$ cells constitute an interesting target for a novel tuberculosis vaccine.

\section{Of mice and men}

Animal models. Experimental animal models of tuberculosis are central to vaccine development. M. tuberculosis infects and causes disease in a large variety of mammalian species, but the most widely used animal models are mice and guinea pigs, each model with its inherent advantages and disadvantages. The currently used vaccine BCG confers protection on mice and guinea-pigs in terms of reduction of the bacterial load by one to two and two to four orders of magnitude, respectively, though sterile eradication is usually not achieved $^{72}$. This is generally accepted as good protection, which implies that vaccine testing is carried out in models in which BCG 'works'. Different animal models should be further exploited to include models of latent tuberculosis for assessing post-exposure and therapeutic vaccines, as well as models that consider immunomodulatory influences of environmental mycobacteria ${ }^{6,73-76}$. Significantly, standardized protocols that emphasize issues that are relevant to human vaccination are urgently required for a reliable comparison between vaccine candidates. There is an urgent need to identify the optimal experimental strategies and to comparatively assess efficacy of different vaccine candidates. A great promise lies in the establishment of a tuberculosis vaccine programme by the National Institutes of Health, and establishment of similar endeavours by the European Community.

Pathology of tuberculosis in mice and humans varies considerably $^{72}$. Despite this, mouse tuberculosis research remains attractive because of our thorough knowledge of the mouse immune system and the availability of various strains of knockout mice. Guinea-pigs are more 


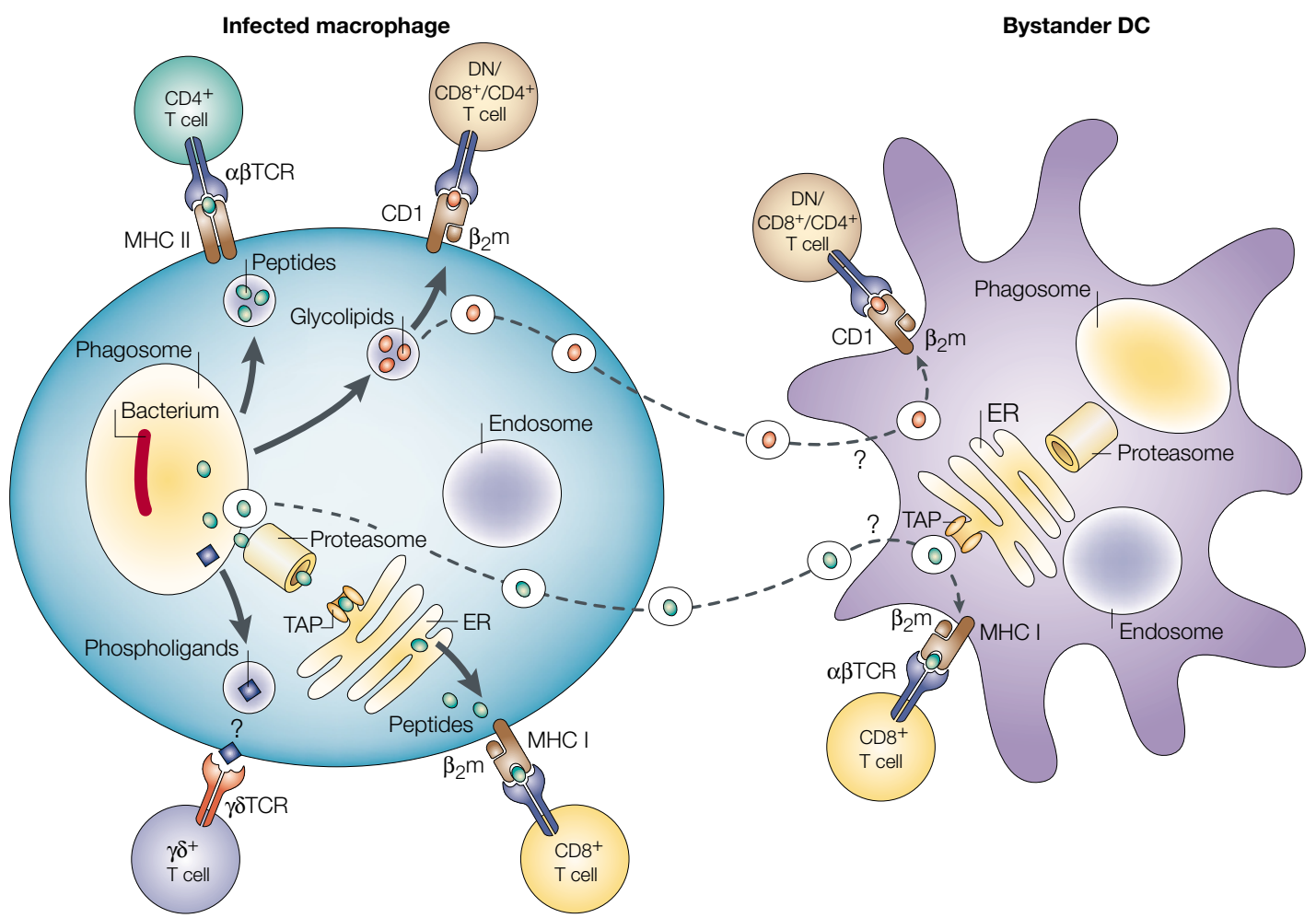

Figure 3 | Antigen processing/presentation pathways and activation of different T-cell subsets. The different T-cellprocessing pathways that result in activation of distinct T-cell populations in the immune response against Mycobacterium tuberculosis are shown. This pathogen preferentially resides in the phagosome of macrophages, where mycobacterial peptides have ready access to the major histocompatibility complex class II (MHC II) molecules that are shuttled to the cell surface and stimulate CD4 ${ }^{+} \mathrm{T}$ cells. CD1 molecules also have access to mycobacterial glycolipids because they have contact with the phagosomal continuum at different stages of its maturation - glycolipids seem to separate from the mycobacteria and are incorporated into vesicles, which are shuttled throughout the cells and also seem to transfer antigen to bystander cells. CD1 molecules present mycobacterial glycolipids to various CD1-restricted T lymphocytes (CD4+, CD8 ${ }^{+}$or DN). The processing pathways for ligands for $\gamma \delta \mathrm{T}$ cells and $\mathrm{MHC}$-class-I-restricted T cells remain less understood. Mycobacterial phospholigands reach the cell surface through unknown ways, and are recognized by $\gamma \delta$ T cells in the apparent absence of specialized molecules. Although it is beyond doubt that MHC-class-I-restricted CD8 ${ }^{+} \mathrm{T}$ cells are stimulated by mycobacterial peptides, the underlying mechanisms remain to be established. Some mycobacterial proteins may enter the cytosol and be introduced into MHC-class-I processing pathways, including cytosolic proteasomes and TAP. Mycobacterial peptides and glycolipids may be transferred in vesicles along a novel pathway from infected macrophages to bystander dendritic cells. This could improve antigen presentation through $\mathrm{MHC}$-class-I and CD1 pathways. Formation of these vesicles is probably stimulated during apoptosis of infected cells. $\beta_{2} \mathrm{~m}, \beta_{2}$-microglobulin; DN, double-negative; ER, endoplasmic reticulum; TAP, transporter of antigen processing.

susceptible to M. tuberculosis than humans, but the pathology that ensues resembles the necrotic lesions that develop in humans. Similarly, guinea-pigs, like humans, express group 1 CD1 molecules, and therefore also CD1/glycolipid-specific T cells ${ }^{77}$. The value of glycolipid antigens for vaccination can therefore be assessed in this species. Indeed, preliminary experiments indicate that glycolipids can induce partial protection against tuberculosis in guinea-pigs (C. Dascher and M. Brenner, personal communication). Group 1 CD1 molecules are absent in mice. In this species, $\gamma \delta$ $\mathrm{T}$ cells participate in tuberculosis, but phospholigandspecific responses are not observed. As phospholigand-specific $\gamma \delta$ T cells are also absent in guinea pigs, experimental analysis of this type of in vivo immune response is restricted to non-human primates.

Non-human primates are naturally susceptible to infection with $M$. tuberculosis, and have both phospholigand-specific $\gamma \delta$ T cells and CD1-glycolipidspecific $\mathrm{T}$ cells, but only a limited number of experiments on non-human primates have been carried out to date ${ }^{78,79}$. Primate studies offer the prospects of significant preclinical information after vital evaluation in smaller animal models. Rhesus monkeys (Macaca mulatta) and, more recently, cynomolgus monkeys ( $M$. fasicularis) are the main species used. Both display pathology very similar to that of humans. A recent comparison of these two closely related species has shown that BCG, when administered in clinical doses, protected only cynomolgus monkeys ${ }^{80}$. Though cynomolgus macaques seem to be a promising model for vaccine development, the value of the rhesus macaques should not be underestimated, as they might provide insights into the immune responses of individuals who are susceptible to tuberculosis and not responsive to BCG, so who are in greatest need of a novel vaccine. 
CORRELATES AND SURROGATES OF PROTECTION

A correlate represents a frequent, but not unambiguous, marker of the protective immune response. A surrogate is considered a consistent and reliable indicator of protection. For example, in the case of tuberculosis, although high intereferon- $\gamma$ production correlates with protection it cannot be considered a surrogate of protection.
Correlates and surrogates of protection in humans. Although research into the human immune response against mycobacteria has provided seminal findings, information about human CORRELATES AND SURROGATES OF PROTECTION against tuberculosis remains limited. The delayed-type hypersensitivity response to partially purified tuberculin is indicative of previous encounters with mycobacteria (and challenge with low doses of partially purified tuberculin specifically for M. tuberculosis) ${ }^{25}$. Unfortunately, it is insufficient as a surrogate of protection. The importance of $\mathrm{CD} 4^{+} \mathrm{T}$ cells that produce IFN- $\gamma$ is beyond doubt, but in certain instances IFN- $\gamma$ production and protection were not correlated. Moreover, a distinction between resistant and susceptible individuals, and also between BCG vaccination and latent infection, cannot be based on this alone. The prognostic value of cytokines, such as LT- $\alpha 3$ and TNF- $\alpha$, as well as T-cell types, including $\mathrm{CD} 8^{+} \mathrm{T}$ cells, $\mathrm{CD} 1 /$ glycolipid specific T cells, $\gamma \delta \mathrm{T}$ cells and T cells at different stages of maturation (naive versus memory), together with a panel of test antigens ranging from bacterial lysates to individual antigens present in the vaccine candidates, all need to be considered. Highly sensitive antigen-specific assays, such as the enzyme-linked immunospot (ELISPOT) assay and tetramer techniques, combined with intracellular cytokine staining, will be of great value. Recent advances in DNA chip technology will facilitate global analyses of the host immune responses to tuberculosis, and are expected to provide information on the correlates and surrogates of susceptibility and resistance, as well as of protection ${ }^{81}$. It is hoped that gene profiling of the pathogen and the host will allow the design of tailor-made DNA microarray chips to provide a surrogate of protection. These 'mini chips' would be of immense value for clinial vaccine trials ${ }^{82,83}$.

\section{Vaccine development}

The search for a vaccine against tuberculosis began 110 years ago with great expectations. Only 8 years after discovering the tubercle bacillus in 1882, Robert Koch devised a subunit vaccine for the treatment of tuberculosis, a disease that constituted the worst threat to mankind at the time. This therapeutic vaccine completely failed. The second attempt was initiated 10 years later by the French scientists Calmette and Guérin. After more than 200 passages, they obtained an attenuated strain of M. bovis, the aetiological agent of cattle tuberculosis, which can, though rarely, cause tuberculosis in humans. This attenuated vaccine, now termed BCG (from Bacille Calmette-Guérin) proved more successful. After more than 3 billion administrations, it is still in use today ${ }^{84,85}$. However, it did not match the expectations it evoked. Although BCG prevents disseminated tuberculosis in newborns, it fails to protect against the most common form of the disease, pulmonary tuberculosis in adults ${ }^{1}$. Similarly, natural infection with M. tuberculosis fails to protect against reinfection ${ }^{86}$. It is important to consider whether M. tuberculosis itself is capable of inducing a sufficiently strong immune response. Because the pathogen persists over a lifetime, it is clear that the immune response fails to eradicate it, and therefore cannot be considered optimal. However, the fact that $90 \%$ of infected individuals do not develop the disease strongly supports the notion that the immune response induced by natural infection is capable of preventing disease in most infected individuals. The pivotal question is whether those individuals who do develop the disease do so because their immune response had been affected either by intrinsic susceptibility or exogenous insult. There is little doubt that disease develops once the immune response, that is generally strong enough to keep the pathogen in check, has been weakened by an exogenous insult. The best example of this is co-infection with HIV, which markedly increases the likelihood of developing active tuberculosis from $10 \%$ during lifetime to $10 \%$ during the upcoming year (BOX 2). However, reinfection after successful eradication of a primary infection by chemotherapy does occur ${ }^{87}$. At least, in these individuals, the immune response that is induced by natural infection failed to induce a sufficiently strong immunological memory to prevent secondary infection. This leads us to ask whether a population exists in which the immune systems of the individuals are incapable of producing the appropriate defence mechanisms. Undoubtedly, susceptible populations represent the main targets for any vaccination strategy.

Obviously, a vaccine that can prevent infection with M. tuberculosis would be optimal, but this could only be achieved by the humoral immune system ${ }^{88}$. Most researchers consider prevention of infection by antibodies an unrealistic goal, and consider T cells as important vaccine targets for containing infection. The current vaccine, BCG, might restrain $M$. tuberculosis over a period of time, but the bacteria can persist and might prevail later in life. In principal, this can be explained in two ways: first, the BCG-induced immune response is basically appropriate, but quantitatively too weak to protect against $M$. tuberculosis; or second, the BCG-induced immune response is qualitatively insufficient; that is, it does not stimulate the combination of $\mathrm{T}$ cells that are required for protection. A similar scenario can be envisaged for the immune response following natural infection with M. tuberculosis. At least, in the population in which disease develops as a result of reactivation and reinfection, it is evident that the immune response fails to induce sufficient immunological memory ${ }^{86}$. In either case, a new vaccine would need to be more efficacious than BCG, and induce a protective immune response even in individuals who are highly susceptible to natural infection with M. tuberculosis.

The main types of vaccine candidates are summarized in TABLE 1. As these have been recently reviewed, I will restrict myself to discussing the general strategies for vaccine development ${ }^{1,72,87}$. Two main strategies can be distinguished: the subunit and the whole viable vaccine strategies. Taking the subunit concept to the extreme implies that induction of a single T-cell population is sufficient for protection. This favours the design of a subunit vaccine that consists of a single protective antigen. The strategy comprises three steps: identification of the protective antigen, definition of the relevant 
T-cell population, and design of an adjuvant that induces the appropriate milieu for this T-cell population. Although this strategy generally focuses on $\mathrm{CD}^{+}$ $T$ cells and on adjuvants that are directed at potent $T_{H} 1$ stimulation, an extended subunit vaccine might consist of protein antigens for MHC-class-II- and MHCclass-I-restricted $\mathrm{T}$ cells, as well as phospholigands for $\gamma \delta$ T cells, and glycolipids that are presented by CD1.

The viable mycobacterial vaccine approach attempts to activate all of the various T-cell subpopulations to achieve the optimal response. The different $\mathrm{T}$-cell populations vary subtly in their effector functions, and they have different requirements for activation. For example, MHC class I molecules are more broadly distributed among host cells than MHC class II and CD1 molecules ${ }^{25}$. Although macrophages serve as an important habitat for M. tuberculosis, the pathogen might also hide in some other cells that do not constitutively express MHC class II and CD1, such as lung parenchyma cells. $\gamma \delta$ T cells are more rapidly activated than conventional $\mathrm{T}$ cells and hence could perform early defence functions. CD1-presented glycolipids are abundant in the cell wall, comprising a rich source of antigen ${ }^{29,89}$.

Subunit vaccines. The elucidation of the M. tuberculosis genome has paved the way for the identification of candidate vaccine antigens ${ }^{3}$. It is unlikely that computer analyses alone will lead directly to the identification of such candidates, as very little is known about the characteristic features of protective antigens for $\mathrm{T}$ cells. Secreted and cell-bound antigens have so far been regarded as superior to intracellular antigens. The straightforward feature of abundance of antigen is also considered valuable for protection. Proteins present in M. tuberculosis and absent in BCG represent putative protective antigens (BOX 1). The two antigens most thoroughly analysed in DNA-vaccination studies in experimental animals - antigen 85 and heat-shock protein 60 (Hsp60) — could not be more different ${ }^{89,90}$.

\begin{tabular}{|c|c|c|c|c|}
\hline Vaccine candidate & Potential advantage & Potential disadvantage & Examples & ence \\
\hline \multicolumn{5}{|l|}{ Subunit vaccine } \\
\hline Antigen in adjuvant & Mild side effects only & $\begin{array}{l}\text { Restricted number of T-cell clones, } \\
\text { primarily CD4+ T cells, immunogenicity } \\
\text { depends on adjuvant type }\end{array}$ & $\begin{array}{ll}\text { Culture filtrate (ill-defined } \\
\text { antigen mixture) } \\
\text { Defined antigen: } & \text { ESAT-6 } \\
& \text { Mtb } 8.4 \\
& \text { Ag85 } \\
\text { Fusion protein: } & \text { Ag85-ESAT-6 }\end{array}$ & $\begin{array}{r}112 \\
113 \\
114 \\
112 \\
98\end{array}$ \\
\hline Naked DNA & CD4 plus CD8 T cells & $\begin{array}{l}\text { Restricted number of T-cell clones, } \\
\text { conventional T cells, safety concerns }\end{array}$ & $\begin{array}{l}\text { Hsp60 } \\
\text { Ag85 } \\
\text { Mtb } 8.4 \\
\text { Therapeutic vaccination }\end{array}$ & $\begin{array}{r}90 \\
91 \\
114 \\
74\end{array}$ \\
\hline $\begin{array}{l}\text { Recombinant carrier } \\
\text { expressing antigen }\end{array}$ & CD4 and/or CD8 T cells & $\begin{array}{l}\text { Restricted number of T-cell clones, } \\
\text { safety concerns }\end{array}$ & $\begin{array}{l}\text { r-Vaccinia expressing Ag85 } \\
\text { r- Salmonella expressing Ag85 }\end{array}$ & $\begin{array}{l}108 \\
115\end{array}$ \\
\hline \multicolumn{5}{|l|}{ Viable mycobacterial vaccine } \\
\hline $\begin{array}{l}\text { Mycobacterium tuberculosis } \\
\text { deletion mutant }\end{array}$ & $\begin{array}{l}\text { CD4 plus CD8 T cells, } \\
\text { unconventional T cells }\end{array}$ & Safety concerns, immunosuppressive & $\begin{array}{l}\text { Erp-M. tuberculosis } \\
\text { Acr-M. tuberculosis } \\
\text { Icl-M. tuberculosis } \\
\text { PcaA-M. tuberculosis } \\
\text { Pdim-M. tuberculosis }\end{array}$ & $\begin{array}{r}116 \\
117 \\
26 \\
118 \\
119\end{array}$ \\
\hline Auxotrophic mutant & Improved safety (BCG) & $\begin{array}{l}\text { Reduced immunogenicity, safety } \\
\text { concerns (M. tuberculosis) }\end{array}$ & $\begin{array}{l}\text { Met, Leu, Ilv-BCG } \\
\text { Met, Pro, Trp M. tuberculosis }\end{array}$ & $\begin{array}{l}120 \\
121\end{array}$ \\
\hline rBCG expressing cytolysin & $\begin{array}{l}\text { CD4 plus CD8 T cells, } \\
\text { unconventional T cells }\end{array}$ & $\begin{array}{l}\text { Devoid of TB-specific antigens, } \\
\text { safety concerns }\end{array}$ & rBCG-listeriolysin & 100 \\
\hline rBCG expressing cytokine & Improved immunogenicity & $\begin{array}{l}\text { Primarily CD4 T cells, devoid } \\
\text { of TB-specific antigens, } \\
\text { safety concerns }\end{array}$ & rBCG-IL-2,-IFN- $\gamma$ & 102 \\
\hline rBCG overexpressing antigen & Improved immunogenicity & Primarily CD4 T cells, safety concerns & rBCG-Ag85 & 122 \\
\hline \multicolumn{5}{|l|}{ Combination vaccine } \\
\hline $\begin{array}{l}\text { rBCG coexpressing } \\
\text { immunomodulator plus antigen }\end{array}$ & $\begin{array}{l}\text { Improved immunogenicity, } \\
\text { protective antigens }\end{array}$ & Safety concerns & Not done & \\
\hline $\begin{array}{l}\text { rM. tuberculosis deletion } \\
\text { mutant expressing } \\
\text { immunomodulator }\end{array}$ & Improved immunogenicity & Safety concerns & Not done & \\
\hline Prime boost & Improved immunogenicity & Safety concerns & $\begin{array}{l}\text { BCG } \rightarrow \text { protein (Ag85) } \\
\text { Naked DNA } \rightarrow \text { protein (Ag85) } \\
\text { Naked DNA } \rightarrow \text { Vaccinia (Ag85) } \\
\text { Naked DNA } \rightarrow \text { BCG }\end{array}$ & $\begin{array}{l}106 \\
107 \\
108 \\
109\end{array}$ \\
\hline
\end{tabular}

Information adapted from REF. 1. Acr, a cognante of the $\alpha$-crystallin family of low-molecular-mass heat-shock proteins (Hsps); Ag85, antigen 85; Erp, a secreted protein of M. tuberculosis; BCG, Bacille Calmette-Guérin; ESAT-6, early secreted antigenic target 6 kDa protein; Icl, isocitrate lysase; IFN- $\gamma$, interferon- $\gamma$; IL-2, interleukin-2; Ilv, either isoleucine, leucine or valine; PcaA, mycolic acid cyclopropane synthase; Pdim, phthiocerol dimycocerosate; rBCG, recombinant BCG; TB, tuberculosis. 
ATTENUATION

A process that reduces the capacity of a pathogen to cause disease. This can occur due to auxotrophy or loss of virulence.

PRIME-BOOST VACCINATION When a single application of a vaccine is insufficient, repeated immunizations are performed using the same vaccine preparation (homologous prime boost) or using differen vaccine preparations (heterologous prime boost) to sequentially stimulate a better immune response.
Cognates of the antigen 85 complex are secreted proteins specific to mycobacteria, whereas Hsp60 is a highly conserved intracellular antigen with homologues in various other microbes and in humans, which causes cross-reactivity ${ }^{92}$. Mycobacterial Hsp60 has been found to contribute to autoimmune diseases in several animal models, and mouse $\mathrm{CD}^{+} \mathrm{T}$ cells cross-reactive with mycobacterial and mammalian Hsp60 have been shown to cause lethal autoimmune disease $\mathrm{e}^{93}$. When selecting antigen candidates, it is important to consider the potential risks of inducing pathological and autoimmune responses ${ }^{92,94}$.

Because no rules defining protective antigens have been formulated, candidate vaccine antigens must be screened for protective efficacy. For this purpose, nakedDNA constructs or DCs loaded with defined antigens seem to be the most appropriate. Alternatively, an unbiased approach is pursued, in which the entire genome is screened for vaccine activity following immunization with an expression library. Such an approach has already been used with some success in various infection models ${ }^{95-97}$. When single protective antigens have been identified, novel forms of the antigens, such as fusion proteins that comprise the immunodominant regions of a panel of antigens, can be easily created using molecular biotechnology ${ }^{98}$. Apart from selection of suitable antigens, the generation of an optimal subunit vaccine will require consideration of which adjuvants will be most appropriate ${ }^{99}$. As our understanding of immune regulation and the role of cytokines, DCs and co-stimulatory molecules increases, new adjuvant strategies will be developed.

Viable mycobacterial vaccines. In humans, neither BCG nor $M$. tuberculosis induce immune responses that cause satisfactory control, let alone eradication, of tubercle bacilli ${ }^{1}$. Hence strategies to improve BCG or attenuate $M$. tuberculosis need to be exploited, and they need not be mutually exclusive. Viable vaccine constructs could be improved by the overexpression of defined protective antigens and by the targeted deletion of others that might contribute to virulence. For example, BCG is a weak inducer of MHC-class-I-restricted $\mathrm{T}$ cells, and it will be important to improve the introduction of antigens into the MHC class I pathways. The immunogenicity of BCG can also be improved by cytokines co-administered with, or expressed in recombinant form by, the BCG vaccine itself. Precedents for the feasibility of this strategy have been already documented $^{100-102}$. The genome of $M$. tuberculosis provides a guide for the rational construction of $M$. tuberculosis deletion mutants ${ }^{3}$ (BOX 1). Several putative virulence factors in its genome have already been identified. These include phospholipases, lipases and esterases that could modify the phagosomal membrane, as well as ferritin-like proteins involved in iron-scavenging in the phagosome, and haemoglobin-like genes, which mediate resistance to RNI. A large-scale comparative analysis between the genomes of $M$. tuberculosis and other pathogens will undoubtedly show additional putative virulence factors.
M. tuberculosis effectively impairs the protective immune response that is mediated by both macrophages and T cells. Evidence has been presented indicating that mycobacteria impair MHC class II, $\mathrm{MHC}$ class I and CD1 presentation, thereby reducing T-cell stimulation ${ }^{3,67,103,104}$. Mycobacteria impair various macrophage-effector function - most notably, arrest of phagosome maturation, as well as inhibition of the generation of ROI and $\mathrm{RNI}^{7,105}$. Therefore, rational ATTENUATION of mycobacteria cannot restrict itself to deletion of classical virulence factors, but must also include the elimination of components that are inhibitory to the immune response. Because at least some of these inhibitory components are non-proteinaceous, such as sulphatides and glycolipids, it would be necessary to delete the appropriate key enzymes in the respective metabolic pathways.

Combination vaccines. Given the protective value of BCG in newborns, it would be ethically unwise to terminate BCG vaccination immediately on introduction of a new vaccine. Hence, a novel vaccine candidate can rely on the immune response induced by BCG. This needs to be taken into account when designing vaccination schedules that use priming with BCG and boosting with the new vaccine ${ }^{106}$. Other combinations currently under investigation include: heterologous PRIME-BOOST VACCINATION comprising naked-DNA vaccination followed by BCG, protein antigen or vaccine carriers, such as a modified vaccinia virus Ankara, expressing the same antigen (TABLE 1). Some increase in protection has been reported using prime-boost vaccinations with antigen 85 , providing a precedence for strategies of this type $\mathrm{e}^{107-109}$.

\section{Concluding remarks}

Vaccination is considered to be the most cost-effective intervention measure in medicine, and vaccines are sometimes mistakenly regarded as magic bullets. Unfortunately, this is not the case, and the assumption that vaccines protect against infection is largely wrong. Often, in fact, vaccines provide protection against disease, without directly eliminating the pathogen. The value of a vaccine becomes questionable if it only manages to prevent the development of the disease, but allows the pathogen to persist within the host so that the disease might redevelop at a later point. This is exactly the case with tuberculosis. Both M. tuberculosis and BCG induce an immune response that can contain infection at least partially, but ultimately fails to prevent the development of disease. Promising vaccine candidates are currently being developed on the basis of different strategies that should be explored in parallel, and the best candidates should be comparatively evaluated. The combined information from recent studies of natural infection with M. tuberculosis and vaccination with BCG, combined with information from the M. tuberculosis genome, transcriptome and proteome, offer good prospects for the development of an efficacious new vaccine $^{3,81,110}$ 
1. Kaufmann, S. H. E. Is the development of a new tuberculosis vaccine possible? Nature Med. 6, 955-960 (2000)

2. World Health Organisation. The World Health Report 2000 Health Systems: Improving Performance (WHO, Geneva, 2000)

3. Cole, S. T. et al. Deciphering the biology of Mycobacterium tuberculosis from the complete genome sequence. Nature 393, 537-544 (1998).

This seminal paper, describing the $M$. tuberculosis genome, provides the blueprint for the identification of antigens, virulence factors and so on of the of antigens,

4. Cole, S. T. \& Barrell, B. G. Analysis of the genome of Mycobacterium tuberculosis H37Rv. Novartis Found. Symp. 217, 160-172 (1998).

5. Ramakrishnan, L., Federspiel, N. A. \& Falkow, S. Granuloma-specific expression of Mycobacterium virulence proteins from the glycine-rich PE-PGRS family. Science 288, 1436-1439 (2000).

6. Manabe, Y. C. \& Bishai, W. R. Latent Mycobacterium tuberculosis - persistence, patience, and winning by waiting. Nature Med. 6, 1327-1329 (2000).

7. Schaible, U. E., Collins, H. L. \& Kaufmann, S. H. Confrontation between intracellular bacteria and the immune system. Adv. Immunol. 71, 267-377 (1999).

8. Ernst, J. D. Macrophage receptors for Mycobacterium tuberculosis. Infect. Immun. 66, 1277-1281 (1998).

9. Ehlers, M. R. \& Daffe, M. Interactions between Mycobacterium tuberculosis and host cells: are mycobacterial sugars the key? Trends Microbiol. 6 , 328-335 (1998).

10. Gatfield, J. \& Pieters, J. Essential role for cholesterol in entry of mycobacteria into macrophages. Science $\mathbf{2 8 8}$ 1647-1650 (2000).

11. Armstrong, J. A. \& Hart, P. D. Phagosome-lysosome interactions in cultured macrophages infected with virulen tubercle bacilli: reversal of the usual nonfusion pattern and observations on bacterial survival. J. Exp. Med. 142, 1-16 (1975).

12. Brightbill, H. D. et al. Host defense mechanisms triggered by microbial lipoproteins through toll-like receptors. Science 285, 732-736 (1999).

13. Schorey, J. S., Carroll, M. C. \& Brown, E. J. A macrophage invasion mechanism of pathogenic mycobacteria. Science invasion mechanism of $p$.

14. Thoma-Uszynski, S. et al. Induction of direct antimicrobial activity through mammalian toll-like receptors. Science 291, 1544-1547 (2001)

15. Russell, D. G., Dant, J. \& Sturgill-Koszycki, S. Mycobacterium avium- and Mycobacterium tuberculosiscontaining vacuoles are dynamic, fusion-competent vesicles that are accessible to glycosphingolipids from the host cell plasmalemma. J. Immunol 156, 4764-4773 (1996).

16. Harth, G. \& Horwitz, M. A. An inhibitor of exported Mycobacterium tuberculosis glutamine synthetase selectively blocks the growth of pathogenic mycobacteria in axenic culture and in human monocytes: extracellular proteins as potential novel drug targets. J. Exp. Med. 189, 1425-1435 (1999).

17. Ferrari, G., Langen, H., Naito, M. \& Pieters, J. A coat protein on phagosomes involved in the intracellular survival of mycobacteria. Cell 97, 435-447 (1999).

18. Lounis, N. et al. Iron and Mycobacterium tuberculosis infection. J. Clin. Virol. 20, 123-126 (2001).

19. Andrews, N. C. Iron metabolism: iron deficiency and iron overload. Annu. Rev. Genomics Hum. Genet. 1, 75-98 (2000).

20. Collins, H. L. \& Kaufmann, S. H. E. The many faces of the host response to tuberculosis. Immunology 103, 1-9 (2001)

21. Schaible, U. E., Sturgill-Koszycki, S., Schlesinger, P. H. \& Russell, D. G. Cytokine activation leads to acidification and increases maturation of Mycobacterium avium-containing phagosomes in murine macrophages. J. Immuno/ $\mathbf{1 6 0}$ 1290-1296 (1998).

22. MacMicking, J. D. et al. Identification of nitric oxide synthase as a protective locus against tuberculosis. Proc. Natl Acad. Sci. USA $94,5243-5248$ (1997).

23. Rich, E. A. et al. Mycobacterium tuberculosis (MTB)stimulated production of nitric oxide by human alveolar macrophages and relationship of nitric oxide production to growth inhibition of MTB. Tubercle Lung Dis. 78, 247-255 (1997)

24. Nathan, C. \& Shiloh, M. U. Reactive oxygen and nitrogen intermediates in the relationship between mammalian hosts and microbial pathogens. Proc. Natl Acad. Sci. USA 97, 8841-8848 (2000)

25. Kaufmann, S. H. E. in Fundamental Immunology 4th edn (ed. Paul, W.) 1335-1371 (Lippincott-Raven, New York, 1999).
26. McKinney, J. D. et al. Persistence of Mycobacterium tuberculosis in macrophages and mice requires the glyoxylate shunt enzyme isocitrate lyase. Nature 406 735-738 (2000).

27. Weber, I., Fritz, C., Ruttkowski, S., Kreft, A. \& Bange, F. C. Anaerobic nitrate reductase (narGHJI) activity of Mycobacterium bovis BCG in vitro and its contribution to virulence in immunodeficient mice. Mol. Microbiol. 35 1017-1025 (2000).

28. Kaufmann, S. H. E. $\gamma / \delta$ and other unconventional T lymphocytes: what do they see and what do they do? Proc. Natl Acad. Sci. USA 93, 2272-2279 (1996).

29. Schaible, U. E. \& Kaufmann, S. H. E. CD1 and CD1restricted T cells in infections with intracellular bacteria. Trends Microbiol. 8, 419-425 (2000).

30. Lin, Y. G., Zhang, M., Hofman, F. M., Gong, J. H. \& Barnes, P. F. Absence of a prominent Th2 cytokine response in human tuberculosis. Infect. Immun. $\mathbf{6 4}$ 1351-1356 (1996)

31. Orme, I. M., Roberts, A. D., Griffin, J. P. \& Abrams, J. S Cytokine secretion by CD4 T lymphocytes acquired in response to Mycobacterium tuberculosis infection. J. response to Mycobacterium tuberd

32. Flynn, J. L. \& Chan, J. Immunology of tuberculosis. Annu. Rev. Immunol. 19, 93-129 (2001).

33. Aderem, A. \& Ulevitch, R. J. Toll-like receptors in the induction of the innate immune response. Nature 406 782-787 (2000).

34. Means, T. K. et al. Human toll-like receptors mediate cellular activation by Mycobacterium tuberculosis. J. Immunol. 163, 3920-3927 (1999).

35. Cooper, A. M. et al. Disseminated tuberculosis in interferon- $\gamma$ gene-disrupted mice. J. Exp. Med. 178, 2243-2247 (1993).

36. Flynn, J. L. et al. Tumor necrosis factor- $\alpha$ is required in the protective immune response against $M y$ cobacterium tuberculosis in mice. Immunity 2, 561-572 (1995).

37. Bean, A. G. et al. Structural deficiencies in granuloma formation in TNF gene-targeted mice underlie the heightened susceptibility to aerosol Mycobacterium tuberculosis infection, which is not compensated for by lymphotoxin. J. Immunol. 162, 3504-3511 (1999).

38. Mohan, V. P. et al. Effects of tumor necrosis factor- $\alpha$ on host immune response in chronic persistent tuberculosis: possible role for limiting pathology. Infect. Immun. 69, 1847-1855 (2001).

39. Roach, D. R. et al. Secreted lymphotoxin- $\alpha$ is essential for the control of an intracellular bacterial infection. J. Exp. Med. 193, 239-246 (2001).

This paper elegantly shows the vital role of lymphotoxin- $\alpha$ in the formation and maintenance of tuberculous granulomas.

40. Feldmann, M. et al. Anti-TNF- $\alpha$ therapy of rheumatoid arthritis: what have we learned? Annu. Rev. Immunol. 19, 163-196 (2001).

41. Maini, R. et al. Infliximab (chimeric anti-tumour necrosis factor- $\alpha$ monoclonal antibody) versus placebo in rheumatoid arthritis patients receiving concomitant methotrexate: a randomised phase III trial. Lancet $\mathbf{3 5 4}$ methotrexate: a ran

42. Myrvik, Q. N., Leake, E. S. \& Wright, M. J. Disruption of phagosomal membranes of normal alveolar macrophages by the H37Rv strain of Mycobacterium tuberculosis. A correlate of virulence. Am. Rev. Respir. Dis. 129, 322-328 (1984).

43. Teitelbaum, R. et al. Mycobacterial infection of macrophages results in membrane-permeable phagosomes. Proc. Natl Acad. Sci. USA 96, 15190-15195 (1999).

44. Beatty, W. L. et al. Trafficking and release of mycobacterial lipids from infected macrophages. Traffic 1, 235-247 (2000).

45. Neyrolles, O. et al. Lipoprotein access to MHC class I presentation during infection of murine macrophages with live mycobacteria. J. Immunol. 166, 447-457 (2001).

46. Schaible, U. E., Hagens, K., Fischer, K., Collins, H. L. \& Kaufmann, S. H. E. Intersection of group I CD1 molecules and mycobacteria in different intracellular compartments of dendritic cells. J. Immunol. 164, 4843-4852 (2000).

47. Fischer, et al. Mycobacterial lysocardiolipin is exported from phagosomes upon cleavage of cardiolipin by a macrophage-derived lysosomal phospholipase $A_{\text {. }}$. macrophage-derived lysosomal phos

48. Yrlid, U. \& Wick, M. J. Salmonella-induced apoptosis of infected macrophages results in presentation of a bacteriaencoded antigen after uptake by bystander dendritic cells. J. Exp. Med. 191, 613-624 (2000)

49. Fayyazi, A. et al. Apoptosis of macrophages and T cells in tuberculosis associated caseous necrosis. J. Pathol. 191, 417-425 (2000)

50. Kaufmann, S. H. E. Killing vs suicide in antibacteria defence. Trends Microbiol. 7, 59-61 (1999).
51. Stenger, S. et al. An antimicrobial activity of cytolytic T cells mediated by granulysin. Science 282, 121-125 (1998).

52. Stenger, S. et al. Differential effects of cytolytic $T$ cell subsets on intracellular infection. Science 276, 1684-1687 (1997).

References 51 and 52 convincingly show the capacity of cytolytic $T$ cells to directly curb mycobacterial growth.

53. Oddo, M. et al. Fas ligand-induced apoptosis of infected human macrophages reduces the viability of intracellular Mycobacterium tuberculosis. J. Immunol. 160, 5448-5454 (1998).

54. Lammas, D. A. et al. ATP-induced killing of mycobacteria by human macrophages is mediated by purinergic P2Z(P2X) receptors. Immunity 7, 433-444 (1997).

55. Flynn, J. L., Goldstein, M. M., Triebold, K. J., Koller, B. \& Bloom, B. R. Major histocompatibility complex class Irestricted $T$ cells are required for resistance to Mycobacterium tuberculosis infection. Proc. Natl Acad. SCi. USA 89, 12013-12017 (1992).

56. Rolph, M. S. et al. MHC class la-restricted T cells partially account for $\beta_{2}$-microglobulin-dependent resistance to 1944-1949 (2001).

57. Behar, S. M. et al. Susceptibility of mice deficient in CD1D or TAP1 to infection with Mycobacterium tuberculosis. J. Exp. Med. 189, 1973-1980 (1999).

58. Sousa, A. O. et al. Relative contributions of distinct MHC class I-dependent cell populations in protection to tuberculosis infection in mice. Proc. Natl Acad. Sci. USA 97, 4204-4208 (1999).

References 56-58 not only underline the importance of MHC class I restricted CD8 ${ }^{+} \mathrm{T}$ cells in defence against tuberculosis, but also show the participation of other $\beta_{2}$ microglobulin-dependent mechanisms.

59. Dother $\beta_{2}$ microglobulin-dependent mechanisms.
Dow. W. et al. Immunization with f-Met peptides induces immune reactivity against Mycobacterium tuberculosis. Tubercle Lung Dis. 80, 5-13 (2000).

60. Chun, T. et al. Induction of M3-restricted cytotoxic T lymphocyte responses by $\mathrm{N}$-formylated peptides derived from Mycobacterium tuberculosis. J. Exp. Med. 193 1213-1220 (2001).

61. Lewinsohn, D. M. et al. Characterization of human $C D 8^{+} T$ cells reactive with Mycobacterium tuberculosis-infected antigen-presenting cells. J. Exp. Med. 187, 1633-1640 (1998).

62. Lewinsohn, D. M., Briden, A. L., Reed, S. G., Grabstein K. H. \& Alderson, M. R. Mycobacterium tuberculosisreactive CD8+ T lymphocytes: The relative contribution of classical versus nonclassical HLA restriction. J. Immunol. 165, 925-930 (2000)

63. Park, S. H. \& Bendelac, A. CD1-restricted T-cell responses and microbial infection. Nature 406, 788-792 (2000).

64. Porcelli, S. A. \& Modlin, R. L. The CD1 system: antigenpresenting molecules for $\mathrm{T}$ cell recognition of lipids and glycolipids. Annu. Rev. Immunol. 17, 297-329 (1999).

65. Ulrichs, T. \& Porcelli, S. A. CD1 proteins: targets of T cell recognition in innate and adaptive immunity. Rev. Immunogenet. 2, 416-432 (2000).

66. Sugita, M. et al. CD1C molecules broadly survey the endocytic system. Proc. Natl Acad. Sci. USA 97, 8445-8450 (2000)

67. Stenger, S., Niazi, K. R. \& Modlin, R. L. Down-regulation of CD1 on antigen-presenting cells by infection with Mycobacterium tuberculosis. J. Immunol. 161, 3582-3588 (1998).

68. D'Souza, C. et al. An anti-inflammatory role for $\gamma \delta \mathrm{T}$ lymphocytes in acquired immunity to Mycobacterium tuberculosis. J. Immunol. 158, 1217-1221 (1997).

69. Ladel, C. H. et al. Contribution of $\alpha / \beta$ T lymphocytes to immunity against Mycobacterium bovis Bacille Calmette-Guérin: studies with T cell receptor-deficient mutant mice. Eur. J. Immunol. 25, 838-846 (1995).

70. Behr-Perst, S. I. et al. Phenotypically activated $\gamma \delta$ T lymphocytes in the peripheral blood of patients with tuberculosis. J. Infect. Dis. 180, 141-149 (1999).

71. Dieli, F. et al. Vy $9 / \mathrm{V} \delta 2$ T lymphocytes reduce the viability of intracelluar Mycobacterium tuberculosis. Eur. J. Immunol 30, 1512-1519 (2000)

72. Orme, M., McMurray, D. N. \& Belisle, J. T. Tuberculosis vaccine development: recent progress. Trends Microbiol. 9, 115-118 (2001).

73. McKinney, J. D. In vivo veritas: the search for TB drug targets goes live. Nature Med. 6, 1330-1333 (2000).

74. Lowrie, D. B. et al. Therapy of tuberculosis in mice by DNA vaccination. Nature 400, 269-271 (1999). This paper shows the value of naked-DNA vaccination in the immunotherapy of tuberculosis.

75. Palmer, C. E. \& Long, M. W. Effects of infection with atypical mycobacteria on BCG vaccination and tuberculosis. Am. Rev. Respir. Dis. 94, 553-568 (1966). 
76. Stanford, J. L., Shield, M. J. \& Rook, G. A. How nvironmental mycobacteria may predetermine the protective efficacy of BCG. Tubercle 62, 55-62 (1981).

77. Dascher, C. C. et al. Conservation of a CD1 multigene family in the guinea pig. J. Immunol. 163, 5478-5488 (1999).

78. McMurray, D. N. A nonhuman primate model for preclinica testing of new tuberculosis vaccines. Clin. Infect. Dis. $\mathbf{3 0}$ S210-S212 (2000).

79. Walsh, G. P. et al. The Philippine cynomolgus monkey (Macaca fasicularis) provides a new nonhuman primate model of tuberculosis that resembles human disease. Nature Med. 2, 430-436 (1996).

80. Langermans, J. A. M. et al. Divergent effect of BCG vaccination on Mycobacterium tuberculosis infection in highly related macque species: Implications for primate models in tuberculosis vaccine research. Proc. Natl Acad. Sci. USA (in the press).

81. Wilson, W. et al. Exploring drug-induced alterations in gene expression in Mycobacterium tuberculosis by microarray hybridization. Proc. Natl Acad. Sci. USA $\mathbf{9 6}$ 12833-12838 (1999). This paper provides the first description of microarrays for the global analysis of tuberculosis.

82. Kaufmann, S. H. E. From genome to function. Microb. Infect. 3, 811-840 (2001).

83. Relman, D. A. \& Falkow, S. The meaning and impact of the human genome sequence for microbiology. Trends Microbiol. 9, 205-208 (2001).

84. Fine, P. E. The BCG story: lessons from the past and implications for the future. Rev. Infect. Dis. 11, S353-S359 (1989).

85. Fine, P. E. M. Variation in protection by BCG: implications of and for heterologous immunity. Lancet 346, 1339-1345 (1995)

86. Van Rie, A. et al. Exogenous reinfection as a cause of recurrent tuberculosis after curative treatment. N. Engl. J. Med. 341, 1174-1179 (1999).

By unequivocally showing reinfection of patients with $\boldsymbol{M}$. tuberculosis after cure of primary infection, this paper emphasizes that natural infection fails to induce complete protection in susceptible individuals.

87. Teitelbaum, R. et al. A mAb recognizing a surface antigen of Mycobacterium tuberculosis enhances host survival. Proc. Natl Acad. Sci. USA 95, 15688-15693 (1998).

88. Collins, H. L. \& Kaufmann, S. H. E. Prospects for better tuberculosis vaccines. Lancet Infect. Dis. 1, 21-28 (2001).

89. Barry, C. E. Interpreting cell wall 'virulence factors' of Mycobacterium tuberculosis. Trends Microbiol. 9 237-241 (2001)

90. Tascon, R. E. et al. Vaccination against tuberculosis by DNA injection. Nature Med. 2, 888-892 (1996).

91. Huygen, K. et al. Immunogenicity and protective efficacy of a tuberculosis DNA vaccine. Nature Med. 2, 893-898 (1996).

References 90 and 91 were the first to document the value of naked-DNA vaccination in tuberculosis value of naked-

92. Zügel, U. \& Kaufmann, S. H. E. Immune response against heat shock proteins in infectious diseases. Immunobiology 201, 22-35 (1999).

93. Steinhoff, U. et al. Autoimmune intestinal pathology induced by hsp60-specific CD8 T cells. Immunity 11 349-358 (1999).

94. Turner, O. C. et al. Lack of protection in mice and necrotizing bronchointerstitial pneumonia with bronchiolitis in guinea pigs immunised with vaccines directed against the hsp60 molecule of Mycobacterium tuberculosis. the hsp60 molecule of Mycobacterium

95. Hoffman, S. L., Rogers, W. O., Carucci, D. J. \& Venter, J. C. From genomics to vaccines: malaria as a model system. Nature Med. 4, 1351-1353 (1998)

96. Melby, P. C. et al. Identification of vaccine candidates for experimental visceral leishmaniasis by immunisation with sequential fractions of a cDNA expression library. Infect. Immun. 68, 5595-5602 (2000).
97. Skeiky, Y. A. W. T cell expression cloning of a Mycobacterium tuberculosis gene encoding a protective antigen associated with the early control of infection. J. Immunol. 165, 7140-7149 (2000).

98. Olsen, A. W., van Pinxteren, L. A. H., Okkels, L. M., Rasmussen, P. B. \& Andersen, P. Protection of mice with a tuberculosis subunit vaccine based on a fusion protein of antigen 85B and ESAT-6. Infect: Immun. 69, 2773-2778 (2001).

99. Vogel, F. R. Improving vaccine performance with adjuvants. Clin. Infect. Dis. 30, S266-S270 (2000).

100. Hess, J. et al. Mycobacterium bovis Bacille Calmette-Guérin strains secreting listeriolysin of Listeria monocytogenes. Proc. Natl Acad. Sci. USA 95, 5299-5304 (1998)

101. Hess, J., Schaible, U., Raupach, B. \& Kaufmann, S. H. E. Exploiting the immune system: toward new vaccines against intracellular bacteria. Adv. Immunol. 75, 1-88 (2000).

102. Murray, P. J., Aldovini, A. \& Young, R. A. Manipulation and potentiation of antibacterial immunity using recombinant Bacille Calmette-Guérin strains that secrete cytokines. Proc. Natl Acad. Sci. USA 93, 934-939 (1996).

103. Pancholi, P., Mirza, A., Bhardwaj, N. \& Steinman, R. M. Sequestration from immune $\mathrm{CD} 4^{+} \mathrm{T}$ cells of mycobacteria growing in human macrophages. Science 260, 984-986 (1993).

104. Hmama, Z., Gabathuler, R., Jefferies, W. A., de Jong, G. \& Reiner, N. E. Attenuation of HLA-DR expression by mononuclear phagocytes infected with Mycobacterium tuberculosis is related to intracellular sequestration of immature class II heterodimers. J. Immunol. 161 4882-4893 (1998)

105. Ting, L. M., Kim, A. C., Cattamanchi, A. \& Ernst, J. D. Mycobacterium tuberculosis inhibits IFN- $\gamma$ transcriptiona responses without inhibiting activation of STAT1. $J$. Immunol. 163, 3898-3906 (1999).

106. Brooks, J. V., Frank, A. A., Keen, M. A., Belisle, J. T. \& Orme, I. M. Boosting vaccine for tuberculosis. Infect. Immun. 69, 2714-2717 (2001).

107. Tanghe, A. et al. Improved immunogenicity and protective efficacy of a tuberculosis DNA vaccine encoding Ag 85 by protein boosting. Infect. Immun. 69, 3041-3047 (2001).

108. McShane, H., Brookes, R., Gilbert, S. C. \& Hill, A. V. S. Enhanced immunogenicity of $\mathrm{CD} 4^{+} \mathrm{T}$-cell responses and protective efficacy of a DNA-modified vaccinia virus Ankara prime-boost vaccination regimen for murin tuberculosis. Infect. Immun. 69, 681-686 (2001).

109. Feng, C. G. et al. Priming by DNA immunization augments protective efficacy of Mycobacterium bovis Bacille Calmette-Guérin against tuberculosis. Infect. Immun. 69 4174-4176 (2001).

110. Jungblut, P. R. et al. Comparative proteome analysis of Mycobacterium tuberculosis and Mycobacterium bovis BCG strains: towards functional genomics of microbie pathogens. Mol. Microbiol. 33, 1103-1117 (1999). The first description of the mycobacterial proteome provides a further means for the identification of antigens, virulence factors and so on.

111. Behr, M. A. et al. Comparative genomics of BCG vaccines by whole-genome DNA microarray. Science $\mathbf{2 8 4}$ 1520-1523 (1999).

This paper used DNA microarray analysis to identify the genes lost in attenuation of BCG, providing a comprehensive list of genes that are absent in BCG and present in $M$. tuberculosis, which constitute potential candidate antigens for vaccination.

112. Horwitz M. A, Lee, B. W. E Dillon, B, J. \& Harth, G Protective immunity against tuberculosis induced by vaccination with major extracellular proteins of Mycobacterium tuberculosis. Proc. Natl Acad. Sci. USA 92, 1530-1534 (1995).

113. Brandt, L., Elhay, M., Rosenkrands, I., Lindblad, E. \& Andersen, P. ESAT-6 subunit vaccination agains Mycobacterium tuberculosis. Infect. Immun. 68, 791-795 (2000).
114. Coler, R. N. et al. Vaccination wtih the T cell antigen Mtb 8.4 protects against challenge with Mycobacterium tuberculosis. J. Immunol. 166, 6227-6235 (2001).

115. Hess, J. et al. Protection against murine tuberculosis by an attenuated recombinant Salmonella typhimurium vaccine strain that secretes the 30-kDa antigen of Mycobacterium bovis BCG. FEMS Immunol. Med. Microbiol. $27,283-289$ (2000).

116. Berthet, F. X. et al. Attenuation of virulence by disruption of the Mycobacterium tuberculosis erp gene. Science $\mathbf{2 8 2}$, 759-762 (1998).

117. Yuan, Y. et al. The 16-KDa-crystallin (ACR) protein of Mycobacterium tuberculosis is required for growth in macrophages. Proc. Natl Acad. Sci. USA 95, 9578-9583 (1998)

118. Glickman, M. S., Cox, J. S. \& Jacobs, W. R. A novel mycolic acid cyclopropane synthetase is required for coding, persistence, and virulence of Mycobacterium tuberculosis. Mol. Cell 5, 717-727 (2000).

Together with reference 26 , this paper was among the first publications to describe $M$. tuberculosis genes that are involved in persistence, and hence constitute interesting targets for the attenuation of constitute interes

119. Cox, J. S., Chen, B., McNeil, M. \& Jacobs, W. R. Jr. Complex lipid determines tissue-specific replication of Mycobacterium tuberculosis in mice. Nature 402, 79-83 (2001).

120. Gukeria, I. et al. Auxotrophic vaccines for tuberculosis. Nature Med. 2, 334-337 (1996).

121. Smith, D. A., Parrish, T., Stoker, N. G. \& Bancroft, G. J. Characterization of auxotrophic mutants of Mycobacterium tuberculosis and their potential as vaccine candidates. Infect. Immun. 69, 1142-1150 (2001).

122. Horwitz, M. A. Harth, G., Dillon, B. J. \& Maslesa-Galic, S Recombinant Bacillus Calmette-Guérin (BCG) vaccines expressing the Mycobacterium tuberculosis 30-kDa majo secretory protein induce greater protective immunity against tuberculosis than conventional BCG vaccines in a highly susceptible animal model. Proc. Natl Acad. Sci. USA 97, 13853-13858 (2000).

This paper describes the superior vaccine efficacy of a recombinant $B C G$ that over expresses an antigen already present in wild-type BCG, and provides precedence for improving BCG as a novel vaccine candidate against tuberculosis.

Acknowledgements

The superb help of L. Lom-Terborg is gratefully acknowledged. thank members of the department for critically reading the manuscript, in particular P. Aichele, H. Collins, B. Raupach, P. Seiler, U. Schaible and T. Ulrichs. I thank J. Langermanns and A. Thomas, and C. Dascher and M. Brenner for sharing unpublished data. I also acknowledge the help of $D$. Schad in preparing the figures. The author's work on tuberculosis receives financial support from the BMBF, EC, German Science Foundation, WHO GPV-VRD and the BMBF, EC,

\section{(D) Online links}

\section{Databases}

The following terms in this article are linked online to:

LocusLink: http://www.ncbi.nlm.nih.gov/LocusLink/

$\beta_{2} \mathrm{~m}|\mathrm{CD} 1 \mathrm{a}| \mathrm{CD} 1 \mathrm{~b}|\mathrm{CD} 1 \mathrm{c}| \mathrm{CD} 1 \mathrm{~d}|\mathrm{H} 2-\mathrm{M} 3|$ HFE $\mid$ Hsp60 | IFNर | IL-4 | IL-10 | IL-18 | LAMP-1 | LT- $\alpha 3$ | Rab7 | TAP | TNF- $\alpha$ |

\section{FURTHER INFORMATION}

National Center for HIV, STD and TB Prevention (Division of Tuberculosis Elimination):

http://www.cdc.gov/nchstp/tb/default.htm

tanford Center for Tuberculosis Research:

http://molepi.stanford.edu/

The Institute for Genomic Research (TIGR): http://www.tigr.org/tigr-scripts/CMR2/CMRHomePage.sp

The Sanger Center: $M$. tuberculosis:

http://www.sanger.ac.uk/Projects/M_tuberculosis/ WHO Global TB Program: http://www who int/gtb/index.htm 